Disclosure of Interests: : None declared DOI: 10.1136/annrheumdis-2020-eular.2904

\section{AB0425 PRELIMINARY EVALUATION OF THE SURAL NERVE USING 24-MHZ ULTRASOUND: A NEW APPROACH TO EVALUATE SURAL NEUROPATHY OF SJOGREN'S SYNDROME PATIENTS}

F. Liu ${ }^{1}$, J. Zhu', S. Zhang ${ }^{1}$, D. LI ${ }^{1}$, F. Liu', W. LI ${ }^{1}$, Y. Liu ${ }^{1} .{ }^{1}$ Peking University People's Hospital, Department of Ultrasound, Beijing, China

Background: Peripheral neuropathy is one of the most frequent extraglandular manifestations of primary Sjögren's syndrome (pSS). The diagnosis of peripheral neuropathy complications of pSS is based primarily on careful neurologic examination and electrodiagnostic tests. The value of ultrasound in peripheral nerve has been recognized. However, little clinical researches have focused specifically on cutaneous nerve of pSS.

Objectives: To evaluate the morphological changes of sural nerve in patients with $\mathrm{pSS}$ by high-frequency ultrasound.

Methods: The prospective study subjects consisted of 31 consecutive pSS patients underwent sural nerve biopsy and 30 healthy volunteers as controls. The ultrasonic presentations of the fascicle, perineurium, epineurium of sural nerve were observed, and the cross-sectional areas (CSA) of the sural nerves was measured.

Results: Among the 21 sural nerves confirmed by pathology, all showed the thickening of the perineurium and epineurium (Figure 1-2), and abnormal blood flow signal in perineurium or epineurium in 14 cases (Figure 2). The mean CSAs were $(1.41 \pm 0.44) \mathrm{mm} 2$ for the control group, and $(1.58 \pm 0.48) \mathrm{mm} 2$ for the case group $(P>0.05)$. In addition, the abnormal blood flow signal in sural nerve correlated with disease activity.

Conclusion: This study indicated that high-frequency ultrasound may be a valuable tool for evaluating cutaneous nerve neuropathy of Sjogren's syndrome patients.

References:

[1] Vitali C, Bombardieri S, Jonsson R, Moutsopoulos HM, Alexander EL, Carsons SE, et al. Classification criteria for Sjögren's syndrome: a revised version of the European criteria proposed by the American-European Consensus Group. Ann Rheum Dis. 2002;61(6):554-8.

[2] Terrier B, Lacroix C, Guillevin L, Hatron PY, Dhote R, Maillot F, et al. Diagnostic and prognostic relevance of neuromuscular biopsy in primary Sjögren's syndrome-related neuropathy. Arthritis Rheum.2007;57(8):1520-9.

[3] McCoy SS, Baer AN. Neurological Complications of Sjögren's Syndrome: Diagnosis and Management. Curr Treatm Opt Rheumatol. 2017;3(4):275-88.

[4] Carvajal Alegria G, Guellec D, Devauchelle-Pensec V, Saraux A. Is there specific neurological disorders of primary Sjögren's syndrome? Joint Bone Spine. 2015;82(2):86-9.

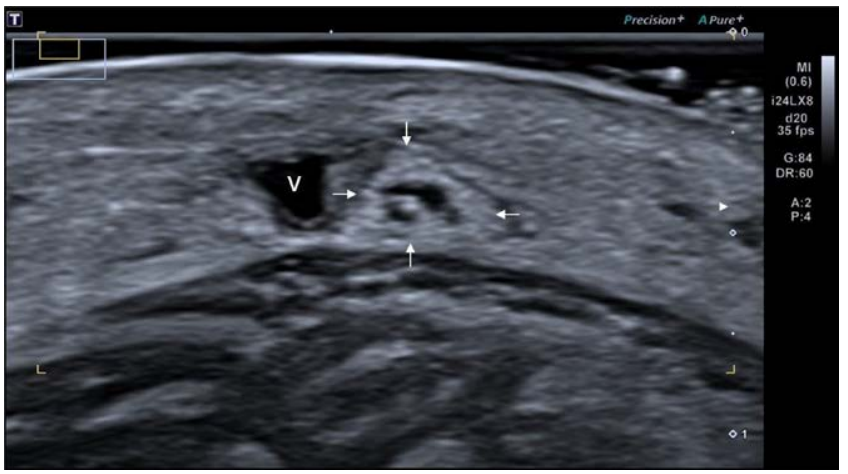

Figure 1. Transverse sonograms of the sural nerve (arrows)V: indicates lesser saphenous vein

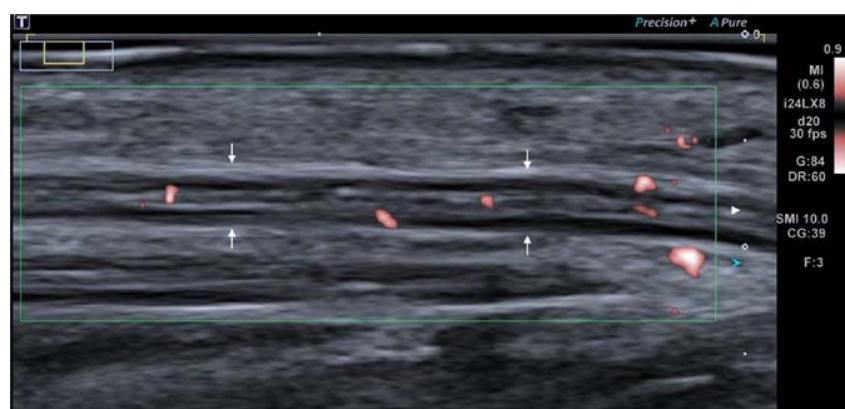

Figure 2. Longitudinal sonograms of the sural nerve (arrows)The sonogram of sural nerve showed abnormal blood flow signal.V indicates lesser saphenous vein.

Acknowledgments: This work was partly supported by National Natural Science Foundation of China (No. 81701712)

Disclosure of Interests: : None declared

DOI: 10.1136/annrheumdis-2020-eular.4176

\section{AB0426 1 FIBROSING INTERSTITIAL LUNG DISEASE IN PRIMARY SJOGREN SYNDROME}

A. Manfredi ${ }^{1}$, C. Vacchi ${ }^{1}$, G. Della Casa ${ }^{1}$, S. Cerri ${ }^{1}$, G. DI Cecco ${ }^{1}$, F. Coppi ${ }^{1}$, F. Luppi ${ }^{2}$, C. Salvarani ${ }^{1}$, M. Sebastiani ${ }^{1}{ }^{1}$ University of Modena and Reggio Emilia, Modena, Italy; ${ }^{2}$ University of Milano-Bicocca, Monza, Italy

Background: Interstitial lung disease (ILD) represents the most frequent pulmonary manifestation of primary Sjogren's syndrome (pSS), with a prevalence ranging between $6-70 \%$ in different retrospectives studies. Non-specific interstitial pneumonia (NSIP) is recognized as the most common ILD disorder, followed by organizing pneumonia (OP), usual interstitial pneumonia (UIP) and lymphocytic interstitial pneumonia (LIP), specifically associated with pSS but less frequent. Objectives: To investigate the prevalence of fibrosing patterns in a monocentric cohort of pSS patients evaluated for lung involvement in a cross-sectional study. Methods: In a cross-sectional study all patients fulfilling ACR/EULAR classification criteria for pSS and with a known diagnosis of ILD were enrolled; the other patients were carefully investigated for signs or symptoms suggestive for ILD (including the search for velcro crackles with a digital device); when suspect, patients underwent to high resolution computed tomography (HRCT). An expert radiologist re-evaluated all HRCT for classifying the ILD pattern as: UIP, fibrotic NSIP, fibrotic OP, NSIP, OP, LIP, indeterminate. Results: One hundred and eighty-five pSS patients were enrolled; among them 34 showed ILD (18.4\%) with the following features: M/F 3/31, median age 57 (range 24-80), median FVC 90\% (39-127\%), median DLCO 49\% (20-84\%). Patients were classified in two groups according to radiologic classification: the group 1 (18 pts 52,9\%) included UIP (13 patients, 38.2\%), fibrotic NSIP (4, 11.8\%), fibrotic OP (12.9\%); the group 2 (16 pts, $47.1 \%)$ included NSIP $(6,17.6 \%)$, OP $(4,11.8 \%)$, indeterminate $(4,11.8 \%)$, LIP (2 $5.9 \%)$. No significant differences were observed between the two groups with the exception of anti-SSB positivity more frequently detected in non-fibrosing pattern ( $p 0,043)$. Conclusion: Despite previous observations, our data suggest a high prevalence of fibrosing ILD pattern in pSS patients. We participate at a multidisciplinary team with expert pulmonologists and radiologists and some patients of our cohort firstly referred to pulmonologist for appearance of ILD before the diagnosis of pSS, contributing to the possible selection of more severe lung disease. However, these data suggest first of all that pSS should always be considered in differential diagnosis of fibrosing ILD; moreover, since fibrosing ILD is thought to have a worse response to immunosuppressive drugs, the role of new possible therapeutic strategies such as anti-fibrotic could represent an important field of interest.

Disclosure of Interests: None declared

DOI: 10.1136/annrheumdis-2020-eular.5769

\section{AB0427 OCCURRENCE OF NEUROPSYCHIATRIC MANIFESTATIONS IN PATIENTS WITH SYSTEMIC LUPUS ERYTHEMATOSUS: RESULTS FROM THE SWISS LUPUS COHORT AND META-ANALYSIS OF THE PERTINENT LITERATURE}

A. L. Meier ${ }^{1,2}$, U. Steiner ${ }^{1}$, L. M. Bachmann ${ }^{2} .{ }^{1}$ University Hospital of Zürich, Dept. of Immunology, Zürich, Switzerland; ${ }^{2}$ Medignition Healthcare Innovations, Zürich, Switzerland 